\title{
SOME POINTS IN THE ETIOLOGY OF INEBRIETY.
}

BY FREDERIC C. COLEY, M.D.

Why does $\mathrm{A}$ become a drunkard, while $\mathrm{B}$ remains through life a moderate drinker? Dr. Archdall Reid tells us that "people differ in their susceptibility to the charm of alcohol," and he says that "we know that all drunkards are so susceptible to the charm that they crave intensely for deep indulgence." And it is essential to Dr. Reid's argument that this peculiar " susceptibility to the charm of alcohol " should be a congenital, and therefore an inherited, idiosyncrasy.

In Dr. Reid's view this inborn tendency to delight in alcohol is the only difference between $A$ and $B$ which is of practical importance. He deliberately rejects, as unworthy of serious consideration, the suggestion of another difference between themviz., strength or weakness of resistance to temptation. $\mathrm{He}$ declares: "This is sheer nonsense in the main, for it carries with it the corollary that all moderate drinkers are constantly tormented by an ardent desire to get drink, which they strenuously resist."

But, to see how unsound this corollary is, we have only to compare a parallel case. An honest man may have as great inducements to theft as those which bring a thief to prison-i.e., he may have as strong (perhaps stronger) reason for wishing to gain possession of property which does not belong to him; and yet he may be quite unconscious of a struggle to resist the temptation to which the thief succumbs. The explanation is perfectly simple. The counter-inducements to honesty are so powerful that the force of temptation is never felt. Of these counterinducements the most generally operative is self-respect. The 


\section{The British Journal of Inebriety}

honest man feels instinctively that the consciousness of being a thief would make him so miserable that no money would be worth it; and this conviction is so strong that it never needs to come beyond the background of the consciousness. This largely accounts for the fact that a man who has once been guilty of a particular offence is very likely to repeat it. His self-respect, such as he has left, is but little wounded by doing again what he has done before.

So, when $\mathrm{B}$ remains moderate in his potations, while $\mathrm{A}$ becomes a drunkard, difference in resisting power may be the explanation, rather than difference in the force of temptation, in spite of the fact that $B$ is not conscious of any need for effort to resist. A child oversets a smaller child with a push; he pushes with all his might in vain against a giant, and the giant is hardly aware of the child's ineffective efforts.

Unquestionably the subjective impression, which Dr. Reid puts forward as a reason for ignoring the different resisting power of different men, is wholly inadequate to justify us in accepting his view. In accounting for the conduct of two men, one of whom succumbs to a temptation and the other does not, we cannot afford to ignore the factor of varying power of resistance, for the excellent reason that such differences in resisting power really do exist, and cannot be wholly inoperative.

But it is when we come to examine the other factor, the varying force of temptation, that the strongest reasons for divergence from Dr. Reid's view present themselves.

Dr. Reid bases all his conclusions upon the subject of practical temperance reform upon the assumption that habitual drunkenness is always and necessarily due to a hereditary (and therefore congenital) "susceptibility to the charm of alcohol." This view of the etiology of alcoholism certainly has the advantage of simplicity. But it is nothing new of simple explanations to find that they will not fit all the facts. No doubt there are some cases in which the briefest possible indulgence in alcohol seems like a match in a powder-magazine. It starts the victim at once on a downward course, which may end only with his life. Congenital idiosyncrasy may account for such catastrophes. But cases like this are not the rule-they are the comparatively rare 
exceptions. The majority of drunkards have proved that they had no congenital craving for drunkenness by the fact that they were moderate drinkers for years before they began to indulge in excess. In the earlier part of their lives they would have declared as confidently as Dr. Reid declares of himself that they felt no inclination to excess. How they came to lose their immunity is a long story, and no two of them would tell it in the same way.

The only motive for drinking to excess which Dr. Reid recognises is the positive gratification which imbibition affords; and as this-in most men, at least-is strictly limited, he assumes that those who take alcohol in excess must be differently constituted from others who take it moderately, but feel no temptation to excess. He can only account for the difference between these two classes by the supposition that they " differ in their susceptibility to the charm of alcohol," and he assumes that this difference must be congenital.

But we cannot afford to forget that alcohol is a narcotic. Those who are paralyzed in presence of the temptation to take alcohol in excess do not so commonly find their inducement in its power to please, but in its power to give present relief from misery of mind or body. The pleasure which alcohol can give is very limited, but bodily pain and anguish of soul have no limits. There is hardly any form of corporal suffering which has not driven some of its victims to alcohol for relief; but it is still more often resorted to as the means of escape from mental distressremorse; the disappointment of failure, or the bitterer disappointment of success which proves to be not worth the price paid to attain it ; business worries; family wretchedness; the "skeleton in the cupboard"; the monotony of an aimless life. Any of these things may make a man a drunkard without the help of any special " susceptibility to the charm of alcohol." Such a man would take it strangely if you spoke to him of the charm of alcohol. You might as well discourse on the charm of a cut throat to a wretch who hoped to find permanent oblivion of his misery by a form of suicide more rapid than alcohol-poisoning commonly is.

The man who flies to alcohol for relief from misery must take his narcotic in ever-increasing doses; for, unfortunately, continued use induces resistance to the analgesic power of the drug, 


\section{The British Journal of Inebriety}

while it gives no immunity from its toxic effects. Hence, everyone who begins to use alcohol as a narcotic for chronic suffering of any kind has started a pathological process. Excessive indulgence produces distress both of mind and body, and the only prospect of relief which the victim can see is to be found in renewed indulgence. What is it to him that the relief is only temporary? He must have it. No doubt he would prefer Hamlet's "bare bodkin" if he were quite free from Hamlet's fears.

The author of the Book of Proverbs understood the pathology of alcoholism better than to call in the detus ex machinat of a supposed congenital "craving for drunkenness." "They have stricken me, thou shalt say, and I was not sick; they have beaten me, and I felt it not. I will seek it yet again." It matters little whether the beating is given with a stick, or with any of the various pathological tortures which follow and punish excess, or with a guilty conscience. The outcome is usually the same- "I will seek it yet again."

The wonder is, not that alcohol should have victims, but that any of them should escape. The man who enjoys three glasses of wine, and could enjoy a fourth, but refuses it because he thinks three as many as will be good for him, exercises a very ordinary prudential self-control, which hardly requires an effort or deserves much praise. The man who resists the craving for alcohol which past indulgences have produced is a hero. That the temperance propaganda has produced thousands of such heroes is no insignificant success. That their number is no larger is surely due to the inherent difficulties of the task which it has undertaken, rather than to any fault in its methods.

Alcohol, like every other narcotic, produces by habitual use a craving for itself. How strong this craving is the subjects of it never know until, by their own choice or by force of circumstances, the customary indulgence is interrupted. While they are taking their daily allowance they declare with the fullest confidence, "I can either take it or leave it." But when they try to "leave it," they commonly discover that their acquired " susceptibility to the charm of alcohol " has become far stronger than they had ever suspected. 
There can be no doubt that a most important advance was made when it was recognised that inebriety is sometimes a disease; but that ought not to lead us to fall into the blunder of supposing that it is always so. If a young man under the influence of bad company takes an excessive quantity of alcohol, the act is a folly, but is no proof of disease. And the consequent intoxication is simply the normal effect of the drug upon previously normal nerve centres. And this folly may be repeated until it becomes a habit, without giving us fair reason to call it a disease. But after a sufficient continuance of that habit the alcohol produces definite, recognisable structural changes in the nerve centres. And as in the acute poisoning, which we call mere drunkenness, so also in the chronic alcoholic degenerations, the highest centres are most readily affected. And the highest centres are always those which are concerned in self-control; hence the emotional instability and the infirmity of purpose of the chronic inebriate.

Inebriety, therefore, especially in its earlier stages, is not necessarily a disease at all; still less is it necessarily a congenital disease. That congenital defects are concerned more or less in the production of some cases of inebriety I do not, of course, deny. That such congenital defects may be factors, even when they are not the main cause of the condition, is probable; but in the majority of cases there is no reason to assume the existence of any congenital predisposition. It cannot be too strongly maintained that any man, however healthy his nerve centres may have been originally, is perfectly capable of becoming an inebriate. There is no such thing as absolute immunity from alcoholism.

The most plausible argument in favour of Dr. Reid's view, that heredity alone explains the difference between $A$ and $B$, is found in the various amounts of alcoholism in different nations and races. But before we agree to throw the whole responsibility upon heredity, we must inquire what other factors may have been involved. And that, I need scarcely say, is a very large question. But to ignore it, and assume that heredity is the only, or even the dominant, factor in producing the varying incidence of alcoholism, is unwarranted.

In individuals we know that a craving for alcohol is established by continued indulgence, where no such craving showed itself 


\section{The British Journal of Inebriety}

when the habit of drinking was only recently formed. This fact alone is enough to make it necessary to look for explanations other than heredity in accounting for the different degrees in which different nations suffer from the curse of inebriety.

Among English working people (who form, of course, by far the largest part of the community) there is an absurd custom which makes thousands of drunkards without requiring any help from hereditary tendency. Two or three working men are going home on Saturday evening, with their week's pay in their pockets. As they pass a public-house, one of them suggests that they should go in and "have a drink." The others may have but little desire to do so, but they hate to be thought stingy or unsociable. Wherefore they consent. Now, it is contrary to the rules of the game for each man to buy and pay for his own glass. One must "treat" all. Then it becomes necessary for each of the rest to "stand treat," or else he would feel (and dread to be called) mean. So each man gets three or four glasses. Then they are ready to become the victims of the fool who suggests "glasses round again." And this miserable folly is repeated week after week, until the cerebral vessels of the victims are in as bad condition as the vessels of their nose-ends. And by that time inebriety has become a disease with them. But it is an acquired disease-not congenital.

When Dr. Reid argues to prove that alcoholic indulgence on the part of parents does not make them more liable to produce an offspring cursed with a congenital tendency to delight in drunkenness, he is in conflict with an opponent who, so far as I know, does not exist. No such conception as that exists in the minds of most of us when we speak of heredity as an occasional factor in the production of inebriety.

There is, in fact, a curiously perfect analogy between heredity in alcoholism and heredity in tuberculosis. Before Koch discovered that the tubercle bacillus was the true causa causans of phthisis, it was not unreasonable to suppose that a tubercular constitution was directly inherited. We now perceive that nothing of the kind happens. We recognise that many cases which were formerly supposed to be due to hereditary tendency are really to be accounted for by contagion. (And here the analogy presented by alcoholism must not be forgotten. There is such a thing as moral contagion. Moreover, the constant and abundant presence of alcohol in a house is a temptation to the younger members of 
the family.) But allowing for the risks of contagion, we still admit that heredity plays a real part in the causation of some cases of phthisis, although not so large a part as was once supposed. No longer imagining that phthisis, as such, is inherited, we recognise that a man may receive from his parents a feeble constitution which is incapable of maintaining an effective struggle against the bacilli of tubercle, if those objectionable microbes should chance to gain an entrance into his body. But we know also that such feeble resisting-power is not necessarily hereditary. It may be acquired, for instance, by the debility following influenza, etc.

And when we consider the problem of prevention of consumption, we do not propose to leave it alone until the beneficent working of the law of survival of the fittest has produced a race endowed with congenital immunity. Nor do we attribute mainly to the working of that law the fact that phthisis is now only half as common as it was fifty years ago. Fifty years is not nearly long enough for evolution to produce such a result. We attribute it rather to improved hygiene, better food, etc.

No doubt some zealous advocates of total abstinence have too hastily assumed, and too confidently asserted, that habitual drunkenness in the parents is likely to result in the transmission to their offspring of a constitutional inability to resist the temptation to inebriety. And Dr. Reid has done well in reminding them that in this assumption they have run counter to a theory which is accepted by the majority of authorities on evolution at the present day. But we must not forget that, although their assertions may be questionable in theory, practically they are not so very far from the truth. The children of a drunkard are in greater danger of becoming drunkards than the children of a teetotaler are for many reasons. There is the mere direct effect of example. There is the more subtle, but not less potent, effect of the lowered moral tone: if they give way to drunkenness, they feel that they are only doing what their parents did before them. They are not deterred, as others would be, by the thought of bringing disgrace upon their family. It is true they may have seen much of the misery which drunkenness produces; but even that has ceased to be shocking, by becoming familiar. They know nothing of the happiness of a home where a higher standard of morality is sustained. And the idea of alcohol as a panacea for all human ills is deep-rooted in their minds. 


\section{The British Journal of Inebriety}

The influence, in these and other ways, of drunken habits in the parents upon their children is so strong that the question of heredity becomes one of hardly more than academic interest, when we are considering the causes of inebriety as a prevalent vice: although, in exceptional individual cases, hereditary tendency may be an important, and even a dominant, factor.

I own I do not quite share Dr. Reid's profound reverence for the dogma that "acquired characteristics are not transmissible." That mutilations should not be transmitted is so much in accordance with what we might expect, that the appeal to direct experiment seems hardly necessary. But when it is declared that no acquired characteristic can possibly be transmitted, we may question whether the facts are not overweighted by the inference.

Dr. Reid's further assertion, "that the diseases of parents do not affect in any way, neither for good nor for evil, offspring subsequently born," is one which, I think, most of my readers will perceive to be, in the nature of things, incapable of proof. And $\grave{a}$ priovi it is excessively unlikely that a disease, or a toxic agent, which affects the whole body, including of course the reproductive organs, should have no effect at all upon the germ cells which they produce.

But, for reasons above indicated, these theoretical questions have very slight practical bearing upon the problem of temperance reform.

We are now in a position to formulate several propositions with regard to the causation of inebriety.

I. Alcohol, like other narcotics, tends to establish a craving for itself in all who indulge in it frequently and freely.

2. By reason of the injury which it does to the higher nerve centres, it impairs the natural power of resistance to such craving.

3. Excessive indulgence in alcohol produces distress both of mind and body, which constitutes a fierce temptation to resort to it again as a narcotic.

4. While the craving for alcohol is more readily produced in some people than in others (and that for many other reasons 
beside congenital idiosyncrasy), there is no reason to suppose that any individuals are so constituted that the craving could not be set up in them by sufficient indulgence.

5. The positive gratification derivable from alcohol is by no means the only motive for drinking; and it is far from being the most dangerous one.

6. The incautious use of alcohol as a remedy for disease is quite capable of setting up a dangerous craving for it.

7. In the more cultured classes the motives for self-restraint are stronger: there is reason to expect, therefore, that in inebriates belonging to these classes there will be a somewhat larger proportion in which the lapse is due to hereditary defect.

Before we pass from the consideration of the etiology of inebriety, to the problems of prevention and cure, it is desirable that we should be reminded of the fact that alcoholism has a moral as well as a physical side. No doubt some have considered the moral side too exclusively. But to ignore or minimize it is a still more serious blunder. The temptation to do so lies in the fact that the physical aspect is the one which lends itself most readily to scientific investigation. And the same temptation leads some people to seek for drugs which may be relied on as specific antidotes for the craving for drink. I would as soon believe in the notorious pills for earthquakes! In some cases physical causes have a part in the etiology of alcoholism. And in some cases medical treatment has a place in aiding the cure. But thousands of cases of alcoholism occur in the production of which physical conditions had no appreciable share, and thousands of cases have been cured by moral means alone.

Dr. Reid offers for comparison two methods of getting rid of the evil of alcoholism: "the reformer's plan, the elimination of drink ; and Nature's plan, the elimination of the drunkard."

What Dr. Reid calls “ Nature's plan" has not been a brilliant success in our own country. For more than 800 years drunkenness has been the national vice of Anglo-Saxons. And it is their national vice still.

And over the greater part of Europe alcohol is becoming more and more recognised as the most dangerous enemy to the health and prosperity and morals of the various nations. Of late years 


\section{The British Journal of Inebriety}

inebriety has been increasing in France to an appalling extent. And the best consolation which Dr. Reid can give is that not very cheering familiar prophecy, "You will have to be worse before you are better!"

After all, there is no reason to expect very much from "Nature's plan." As I have shown, heredity plays a very subordinate part in the causation of inebriety. But, beside that, alcohol is an agent peculiarly unsuited for the work of eliminating the unfit. Habitual indulgence in it does certainly tend to shorten life. But death from alcoholism does not usually take place until well on in middle age-i.e., not until there has been time for the production of a numerous progeny.

What we see in the history of our own country, viz., the absolute failure of alcohol to produce an immunity from its own evil effects, is exactly what a priori reasoning would lead us to expect.

When Dr. Reid tells us that "the reformer's plan has long been out of court," I do not know the authority on which he makes the statement; and I am unable to see good reason for it.

That the temperance propaganda carried on in this country during the last fifty years has been a failure is a statement which would be made by no one who was not in utter ignorance of the facts. Thousands of drunkards have been restored to sobriety; and still larger numbers, who have been brought up in the habit of total abstinence from alcohol, or who have been induced to adopt it early in life, have been preserved from the evils which might have come upon them if their inborn tendencies to excess had ceased to be latent. These facts are none the less certain, although they cannot be put in the form of statistics. To pretend to ignore them on that account may seem to some people scientific, but it is not wise. There is one fact which is sometimes quoted as though it were a proof that the advocacy of total abstinence had been a failure-viz., that the average expenditure on alcohol per capita has not diminished, but has on the whole increased. This is partly accounted for by the deplorable fact that during the last few decades drinking, and consequently inebriety, have fearfully increased among women. The other factor is one which in many, ways is cause for rejoicing, viz., the large increase in the earnings of working people. Unhappily, there always has 


\section{The British Journal of Inebriety}

been, and still is, a very numerous class whose potations are only limited by the amount of drink which they are able to procure. Having of late years more to spend, they have spent more in drink. Hence we find that in prosperous years, when work has been plentiful and highly paid, the national drink bill has increased, and vice versâ. And so it has happened that, while there is an ever-increasing proportion of the population who drink no alcohol at all (and are every way better off for their abstinence), those who still drink are drinking much more.

Those who are bitterly opposed to all that is called temperance legislation are fond of asserting that it has been tried and found a failure. All others feel strongly that it has never been tried in such a way as to show how much can be done by it. In England our legislators have been so anxious not to go beyond public opinion that they have lagged far behind it. In America they are not so cautious about making laws, because they never intend to keep them unless they feel so disposed. The one case is like a remedy administered in a wholly inadequate dose. The other is like a heroic prescription which the patient declines to take.

About a century ago many people found by experience that habitual snuff-taking produced a craving for snuff which was almost as imperious, though not nearly so disastrous in its results, as the craving which alcohol produces for itself. Very few people feel that craving now. No one will argue that this is because snuff-taking eliminated all who had an inborn susceptibility to its fascination. Altered social custom has resulted in this, that very few people indulge in snuff-taking so as to create a craving for it.

May we not hope that, as the result of altered social custom, much fewer people will put themselves in the way of acquiring the craving for alcohol? Social custom used to protect women, except the most degraded of their sex, from the risk of drifting into alcoholism. May we not hope that in time to come social custom may change again, so that both women and men may be free from the perils which it now brings to them? Will it not be wise for us to work to secure this result, rather than trust to what Dr. Reid calls "Nature's method," which has effected nothing appreciable for our country in 800 years?

Dr. Reid makes one exception to his condemnation of all attempts at temperance reform. He approves of the "Gothen- 


\section{The British Journal of Inebriety}

burg System." Now, either this system tends to diminish excessive drinking or it does not. If it does not, it is a failure. If it does, its success can only be ascribed to the lessening of external temptations to excess. In all Dr. Reid's previous argument, he has utterly ignored the force of external temptation, and has insisted that the only cause of excessive drinking worthy of consideration is the supposed congenital " susceptibility to the charm of alcohol." So that in his approval of the Gothenburg System he is logically inconsistent. In which he has shown himself very human. For most men's logic is liable to deflection by their inclinations, like bowls which do not run straight because they are made with a bias to one side. It happens that the Gothenburg System is the one modern scheme of temperance reform which is opposed in principle to teetotalism. Teetotalism assumes (not without abundant evidence) that men can do very well without alcohol altogether. The Gothenburg System assumes (contrary to the evidence) that men cannot, or at least will not, do without alcohol. And Dr. Reid does not like teetotalism.

There is, indeed, one way in which the Gothenburg System might fit into Dr. Reid's scheme with most perfectly logical exactness. It is possible that some, who now practise total abstinence, might be induced to desert their principles by the specious promise which is made of respectability and protection from temptation to excess in the "reformed public-houses." So long as these never tasted alcohol, their inborn susceptibility to its charm might remain latent, and they might live to a happy and honoured old age. But they might perhaps be persuaded to take in a "reformed public-house" what they would have refused to touch elsewhere, with the result that their latent susceptibility might become developed and lead them to drink themselves to death. This is, indeed, the only way in which the Gothenburg System could favour the operation of what Dr. Reid calls "Nature's beneficent plan" for the elimination of the unfit. Such possibilities have been the strongest ground for objecting to the system. But if they are indeed Dr. Reid's motive for approving of it, then its advocates (though not, perhaps, too fastidious about the supporters whom they welcome) might surely exclaim, Non tali auxilio, nec defensoribus istis. 